\title{
Decline in lung function related to exposure and selection processes among workers in the grain processing and animal feed industry
}

\author{
Wendel Post, Dick Heederik, Remco Houba
}

\begin{abstract}
Objectives-To follow up workers in the grain processing and animal feed industry five years after an initial survey, and to monitor exposures to organic dust and endotoxin and changes in prevalence of respiratory symptoms and lung function. Methods-Outcome measures in the present survey were decline in lung function over five years, rapid annual decline in forced expiratory volume in one second $\left(F E V_{1}\right)$ above $90 \mathrm{ml}^{-1}$, and loss to follow up. Results-Among 140 workers included in the longitudinal analysis, annual decline in $F_{E V}$ and maximal mid-expiratory flow (MMEF) were significantly related to occupational exposure to dust and endotoxin in the grain processing and animal feed industry. Assuming a cumulative exposure over a working life of 40 years with an exposure of $5 \mathrm{mg} \cdot \mathrm{m}^{-3}$, the estimated effect on the $\mathrm{FEV}_{1}$ would be a decline of $157 \mathrm{ml}^{-1} \quad(95 \%$ CI 13 to 300 )-that is, about $4 \%$ of the group mean $\mathrm{FEV}_{1}$ and $473 \mathrm{ml} . \mathrm{s}^{-1}(95 \%$ CI 127 to 800$)$ of the MMEF (about 12\%). Workers with a dust exposure $>4 \mathrm{mg} \cdot \mathrm{m}^{-3}$ or endotoxin concentrations $>20 \mathrm{ng} \cdot \mathrm{m}^{-3}$ at the 1986-8 survey had significantly higher risk of rapid decline in $\mathrm{FEV}_{1}$ (odds ratio (OR) 3.3, $95 \% \mathrm{CI} 1.02$ to 10.3$)$. The relations between occupational exposure and decline in lung function in this study occurred, despite the selection through the healthy worker effect that occurred as well. Increasing working years was related to decreasing annual decline in $F_{1} V_{1}$ and fewer people with rapid decline in $\mathrm{FEV}_{1}$ (OR 0.04, 95\% CI 0 to 0.61 for over $20 v<5$ working years in the grain processing and animal feed industry). The presence of respiratory symptoms at baseline was a strong predictor of subsequent loss to follow up. Baseline lung function was not found to be predictive of subsequent loss to follow up. However, among workers lost to follow up the number of working years was more strongly negatively related to baseline lung function than among the workers who were studied longitudinally. Conclusions-The existence of the healthy worker effect implies that an exposureresponse relation in the grain processing and animal feed industry may well be underestimated. This should be taken into account when health based recommended limit values are to be developed.

(Occup Environ Med 1998;55:349-355)
\end{abstract}

Keywords: grain processing industry; animal feed industry; decline in lung function; healthy worker effect

Exposure to organic dusts may cause acute or chronic respiratory symptoms often accompanied by changes in lung function. ${ }^{1}$ Grain dust has been most extensively studied. ${ }^{2-4}$ Other organic dusts which have been studied include dusts associated with the manufacture of coffee, tea, spices, soy, fur, and animal food. ${ }^{1}$

In the mid-1980s a cross sectional study at 14 different sites in the grain processing and animal feed industry in The Netherlands was undertaken to explore relations between exposure to organic dust and respiratory symptoms and chronic changes in lung function. ${ }^{5}$ The findings of this study suggested that both symptoms and lung function were clearly related to (present and historical) exposure to endotoxins. A considerably weaker relation was found for exposure to inspirable dust. This finding is in agreement with exposure studies that show that the airway response to grain dust represents an acute inflammatory response to inhaled toxins, such as endotoxin. ${ }^{6}$ Several investigators have suggested a possible role of endotoxin in the aetiology of chronic bronchitis. ${ }^{78}$ An exposure-response relation of exposure to endotoxins with prevalence of chronic bronchitis, forced expiratory volume in one second $\left(\mathrm{FEV}_{1}\right)$, and byssinosis has been reported in the cotton industry. ${ }^{9}$

Cumulative exposure to organic dust in the grain processing and animal feed industry seemed to affect lung function independently of the present exposure. ${ }^{5}$ This led to the assumption that both present and previous exposure are important predictors of decline in lung function. The effect of exposure to organic dust in the animal feed industry on lung function might at least be partially reversible. ${ }^{510}$

Finally, some observations suggested that exposure related selection was present. Lung function was generally lower in control subjects than in animal feed workers, chronic phlegm was less prevalent in the highest category of dust exposure, and shortness of breath and chest tightness were inversely related to number of years worked in animal feed production. Other studies in the grain industry also found indications of the healthy worker effect. ${ }^{13411}$

Among workers exposed to grain dusts several longitudinal studies have been conducted in which the effect of exposure on change in lung function has been studied. ${ }^{24} 1012$ These studies suggested that annual losses in 
lung function is greater among workers exposed to grain dust than in an unexposed population. ${ }^{4}$ A cumulative effect of exposure has been found $\mathrm{d}^{12}$ as well as a dose-response relation with level ${ }^{210}$ or duration of exposure. ${ }^{4}$ Only in a few epidemiological studies in grain workers has a reliable characterisation of exposure been included, which is necessary to explore exposureresponse relations. In the period 1991-3 another cross sectional study was carried out among the workers still employed at the 14 animal feed mills, and who participated in the original cross sectional study of 1986-8. The goal of this study was to analyse exposureresponse relations for exposure to organic dusts in the grain processing and animal feed industry, with some emphasis on the role of exposure to endotoxins. Furthermore, this study considered the healthy worker effect by studying the correlation of respiratory symptoms and lung function during the first survey with loss to follow up at the second survey.

\section{Subjects and methods}

\section{STUDY POPULATION}

In the study by Smid et al among workers in the grain processing and animal feed industry in The Netherlands, data from 315 people were used in the analysis. ${ }^{5}$ With new information on smoking history, gathered during the second survey, smoking status at the time of the first survey could be established for another five workers. Of those 320 subjects, 144 participated in the second survey and had a complete data set. Four workers had ever worked in maintenance and were therefore excluded from analyses. The 156 workers who participated in the first study, but not in the second, were classified as lost to follow up. Detailed reasons for loss to follow up are not available, as most of the workers had left the work site. However, some (estimated 5\%-10\%) were still employed, but were unable to participate during the second survey, because of illness, holidays, or high workload.

\section{METHODS}

Exposure

In 1986-8 eight hour personal inspirable dust samples were taken from the production workers in eight facilities. Exposure measurements were repeated less intensively during the 1990-2 survey, and especially in those facilities with no previous exposure samples. Gravimetric dust and endotoxin concentrations were measured in the samples with the limulus amoebocyte lysate (LAL) test. Details of sampling methods and analyses are given elsewhere. ${ }^{13}$ Several proxies of exposure were available.

Categories of exposure were:

- High (>10 mg.m $\left.\mathrm{m}^{-3}\right)$ and intermediate (4- $\leqslant 10$ $\left.\mathrm{mg} . \mathrm{m}^{-3}\right)$ dust exposure at the first survey $v$ no or low exposure $\left(\leqslant 4 \mathrm{mg} \cdot \mathrm{m}^{-3}\right)$, or high $(>40$ ng. $\left.\mathrm{m}^{-3}\right)$ and intermediate $\left(20-\leqslant 40 \mathrm{ng} \cdot \mathrm{m}^{-3}\right)$ exposure to endotoxins at first survey $v$ no or low exposure ( $\left.\leqslant 20 \mathrm{ng} \cdot \mathrm{m}^{-3}\right)$.

- Change in exposure category between the first and second surveys: low-high are workers with no or low exposure at the first survey and intermediate or high exposure at the second or workers with intermediate exposure at the first survey and high exposure at the second, high-low are workers with high exposure at the first survey and intermediate or no or low exposure at the second or workers with intermediate exposure at first survey and no or low exposure at second survey $v$ always low workers with no or low exposure at both surveys, and always high workers who had an intermediate or high exposure level at both surveys.

- Average level of exposure during first survey.

- Number of working years in the grain processing and animal feed industry.

- Number of working years with exposure in the grain processing and animal feed industry.

- Cumulative exposure to dust or endotoxin, defined as the number of working days in a specific exposure category multiplied by the average daily level of exposure of each exposure category that the worker has worked in.

These exposure proxies measures were computed for the interval between the first and second surveys, and the period between the time of first employment in the grain processing and animal feed industry and the first survey. These periods add up to the duration of employment in the grain processing and animal feed industry, since first employment until the second survey.

\section{Health examination}

A short self administered questionnaire, which has also been used during the first survey, was used to collect information on respiratory symptoms. ${ }^{5}$ The questions included chronic cough and chronic phlegm, shortness of breath, ever and frequent wheezing, and chest tightness. Forced expiratory lung function measurements were conducted on Mondays between 1100 and 1500 , after at least 48 hours without exposure to organic dusts. Production workers underwent lung function tests shortly before or just after the start of the afternoon shift. Vicatest-V dry rolling seal spirometers (Mijnhardt, Bunnik, The Netherlands) were used. Measurements and procedures, including body temperature and pressure saturated adjustments, were carried out according to the standards of the European Respiratory Society ${ }^{14}$ and were similar to those applied during the first survey. Forced vital capacity (FVC), forced expiratory volume in one second $\left(\mathrm{FEV}_{1}\right)$, peak expiratory flow (PEF), maximum mid-expiratory flow (MMEF) and maximum expiratory flow rates, and $75 \%, 50 \%$, and $25 \%$ of the vital capacity $\left(\mathrm{MEF}_{75 \%}, \mathrm{MEF}_{50 \%}\right.$, and $\left.\mathrm{MEF}_{25 \%}\right)$ were recorded.

STATISTICAL ANALYSES

Exposure characterisation and grouping of mean exposures were evaluated by analysis of variance (ANOVA) of within and between group variance (PROC NESTED). The ratio between these two components of variance were used to evaluate different categorisations of job title groups. Relations between exposures and longitudinal change in lung function were analysed with SAS software. The change 
in lung function was defined as the difference between lung function at the first survey minus the lung function at the second survey and standardised for the time between the surveys. The effects of exposure on lung function, corrected for age, height, and smoking, were studied with linear regression models. Age and height at the time of the second survey and smoking status were included in the regression models as potential confounders. Smokers and former smokers were compared with never smokers. Subjects who smoked in the year preceding or during the first survey and who still smoked during the second survey, or who stopped smoking within a year before the second survey were defined as smokers. Former smokers were defined as people who stopped smoking more than a year before the first survey and had not smoked in the period between the two surveys or who had stopped smoking after the first survey, but more that a year before the second survey. Regression models did not improve with quantitative measures of smoking status-such as number of pack-years of cigarettes. These analyses are not included in this paper.

\section{Results}

EXPOSURE ASSESSMENT

During the first survey 520 personal exposure samples were gathered. Another 179 personal samples were gathered during the second survey. Especially during the first survey, repeated measurements were taken. Therefore, mean exposure per person and function and period could be calculated. This resulted in 187 and 168 personal dust concentrations for several job titles. Except for a significantly

Table 1 Mean dust and endotoxin concentrations per job title and facility

\begin{tabular}{|c|c|c|c|c|c|c|}
\hline & \multicolumn{3}{|c|}{ Dust $\left(m g \cdot m^{-3}\right)$} & \multicolumn{3}{|c|}{ Endotoxin $\left(n g \cdot m^{-3}\right)$} \\
\hline & $\begin{array}{l}12 \\
\text { facilities }\end{array}$ & $\begin{array}{l}\text { Facility } \\
X\end{array}$ & $\begin{array}{l}\text { Facility } \\
Y\end{array}$ & $\begin{array}{l}12 \\
\text { facilities }\end{array}$ & $\begin{array}{l}\text { Facility } \\
X\end{array}$ & $\begin{array}{l}\text { Facility } \\
Y\end{array}$ \\
\hline Unloader & 18.2 & 83.6 & 8.1 & 50.2 & 176.9 & 4.8 \\
\hline Crane driver & 4.0 & & & 69.4 & & \\
\hline Silo operator & 14.1 & & & 30.3 & & \\
\hline Miller & 20.3 & & & 99.0 & & \\
\hline \multicolumn{7}{|l|}{ Production workers: } \\
\hline Facility operator & 1.7 & 17.2 & & 4.6 & 36.2 & \\
\hline Press operator & 3.5 & 9.6 & 5.4 & 4.4 & 20.8 & 13.4 \\
\hline Bulk loader & 5.0 & & 6.1 & 6.9 & & 53.5 \\
\hline Other & 8.5 & & & 33.6 & & \\
\hline Premixer & 5.7 & & & 3.6 & & \\
\hline Sacker & 4.8 & & & 4.7 & & \\
\hline Expedition & 3.0 & & & 19.4 & & \\
\hline Production manager & 2.5 & 8.2 & & 7.8 & 3.0 & 28.8 \\
\hline
\end{tabular}

Table 2 Population characteristics

\begin{tabular}{|c|c|c|}
\hline & $\begin{array}{l}\text { Lost to follow up } \\
(n=156)\end{array}$ & $\begin{array}{l}\text { Included in } \\
\text { longitudinal } \\
\text { analysis } \\
(n=140)\end{array}$ \\
\hline Age during $1986 / 88$ survey $(\mathrm{y}$, mean $(\mathrm{SD})$ ) & $41.8(12.0)$ & $37.7(9.3)^{\star}$ \\
\hline Concurrent working years (mean (SD)) & - & $5.0(0.4)$ \\
\hline Concurrent average dust exposure (mg. $\mathrm{m}^{-3}$, mean $\left.(\mathrm{SD})\right)$ & - & $7.9(9.3)$ \\
\hline Concurrent average endotoxin exposure (ng. $\mathrm{m}^{-3}$, mean (SD)) & - & $24.8(29.0)$ \\
\hline Previous working years (mean (SD)) & $14.9(10.4)$ & $12.5(8.4)^{\star}$ \\
\hline Previous average dust exposure $\left(\mathrm{mg} \cdot \mathrm{m}^{-3}\right.$, mean (SD)) & $6.4(8.0)$ & $7.6(10.8)$ \\
\hline Previous average endotoxin exposure (ng. $\mathrm{m}^{-3}$, mean (SD)) & $20.3(23.1)$ & $23.0(28.7)$ \\
\hline Non-smokers (n (\%)) & $26 \quad(17)$ & $37(26)^{\star \star}$ \\
\hline Smokers (n (\%)) & $94 \quad(60)$ & $74 \quad(53)$ \\
\hline Former smokers (n (\%)) & $36 \quad(23)$ & $29 \quad(20)$ \\
\hline
\end{tabular}

${ }^{\star} \mathrm{p}<0.05, t$ test; ${ }^{\star \star} \mathrm{p}<0.05, \chi^{2}$ test. lower level of exposure to organic dusts for crane drivers $(t$ test, $\mathrm{p}<0.05)$, no differences in average dust concentrations per function category between the first and second surveys were found. Only the average endotoxin concentrations for crane drivers and production managers were significantly lower during the second survey ( $t$ test, $\mathrm{p}<0.05$ ). Combining results of both surveys seemed, therefore, to be justified. The mean concentration per person and function was computed, resulting in a total of 353 personal average exposures. Next, the average exposure per function group was calculated.

A more refined categorisation than the one used in the first cross sectional study was considered essential, as the relatively large number of dust samples in the category "other" allowed distinction of two highly exposed job titles (silo worker and miller). One of the facilities (facility $\mathrm{X}$ ) was found to have a significantly higher average dust and endotoxin concentration for several job titles (unloader, facility operator, press operator, and production manager) than the other facilities. At five facilities with similar production procedures and techniques (referred to as facility Y), unloaders had a significantly lower level of exposure than at the other facilities. The level of exposures of press operators and bulk loaders working at these facilities was higher than the average level at the other facilities. In the present analyses, the optimal categorisation distinguishes 12 instead of the former seven exposure groups and accounts for differences in average exposure between job categories and the different facilities already mentioned. The ratios of the within and between group variance compare favourably with the earlier categorisation into eight job groups and into high, intermediate, or low exposure used in the analyses of the first survey and show a clearer distinction in exposure between relatively homogeneous groups. Table 1 shows the mean concentrations of dust and endotoxin for each job title and facility.

POPULATION CHARACTERISTICS

The average time interval between the surveys was five years. Table 2 shows the mean age, as well as mean exposure concentrations and working years in the period between the surveys (concurrent exposure) and in the period before the first survey (previous exposure) for the 140 workers who attended the two surveys and the 156 workers who participated in the first survey only. Among the 140 workers who attended both surveys, many of the smokers had stopped smoking after the first survey, and no one had started smoking.

RESPIRATORY SYMPTOMS AND LUNG FUNCTION In general, the prevalence of respiratory symptoms is low among the 140 workers who attended both surveys. Less than $5 \%$ of the workers reported chronic respiratory symptoms. Twenty five workers $(18 \%)$ reported at least one of these respiratory symptoms. Ten workers $(7 \%)$ reported one or more of the following chronic obstructive respiratory symptoms: chronic cough, chronic phlegm, or 
Table 3 Respiratory symptoms and lung function among workers lost to follow up and workers included in longitudinal analysis

\begin{tabular}{|c|c|c|c|}
\hline & $\begin{array}{l}\text { Lost to follow up } \\
(n=156) n(\%)\end{array}$ & $\begin{array}{l}\text { Included in longitudinal } \\
\text { analysis }(n=140) n(\%)\end{array}$ & \\
\hline Chronic cough & $20(13)$ & $6(4)^{\star}$ & \\
\hline Chronic phlegm & $12(8)$ & $2(1)^{\star}$ & \\
\hline Shortness of breath & $12(8)$ & $5(4)$ & \\
\hline Ever wheezing & $30(13)$ & $18(13)$ & \\
\hline Frequent wheezing ( $\geqslant 1$ week) & $12(8)$ & $3(2)^{\star}$ & \\
\hline Chest tightness & $8(5)$ & $6(4)$ & \\
\hline$\geqslant 1$ Respiratory symptom & $42(27)$ & $25(18)^{\star \star}$ & \\
\hline $\begin{array}{l}\geqslant 1 \text { Chronic obstructive respiratory symptom } \\
\text { (cough, phlegm, or shortness of breath) }\end{array}$ & $30(19)$ & $10(7)^{\star}$ & \\
\hline \multirow{2}{*}{$\begin{array}{l}\geqslant 1 \text { Asthma-like symptom } \\
\text { (frequent wheeze or chest tightness) }\end{array}$} & $17(11)$ & $8(6)$ & \\
\hline & $\begin{array}{l}\text { 1986-88 Lung function } \\
\text { level mean (SD) }\end{array}$ & $\begin{array}{l}\text { 1986-88 Lung function } \\
\text { level mean (SD) }\end{array}$ & $\begin{array}{l}\text { Annual change in } \\
\text { lung function range }\end{array}$ \\
\hline FVC (1) & $5.22(0.93)$ & $5.44(0.85)^{\star \star \star}$ & -0.165 to 0.094 \\
\hline $\mathrm{FEV}_{1}\left(1 . \mathrm{s}^{-1}\right)$ & $3.96(0.95)$ & $4.24(0.78)^{\star \star \star}$ & -0.159 to 0.103 \\
\hline $\operatorname{MMEF}\left(1 . \mathrm{s}^{-1}\right)$ & $3.51(1.60)$ & $3.97(1.43)^{\star \star \star}$ & -0.272 to 0.327 \\
\hline
\end{tabular}

${ }^{\star} \mathrm{p}<0.05 ;{ }^{\star \star} \mathrm{p}<0.10, \chi^{2}$ test; ${ }^{\star \star \star} \mathrm{p}<0.05, t$ test.

shortness of breath; and eight $(6 \%)$ reported asthma like symptoms: frequent wheezing or chest tightness. Among those lost to follow up, significantly more workers reported chronic cough, chronic phlegm, and frequent wheezing (table 3), and lung function was also significantly lower than among workers who attended both surveys (table 3 ). Among those lost to follow up, eight $(5 \%)$ of the workers had an $\mathrm{FEV}_{1}$ $<70 \%$ predicted (based on age and standing height) and three (2\%) had an $\mathrm{FEV}_{1}<50 \%$ predicted, compared with three $(2 \%)$ and zero $(0 \%)$, respectively, among those who attended both surveys. These differences, however, were not significant. On average, lung function decreased between the two surveys. Table 3 shows the range in annual change in lung function. Nineteen workers (14\%) had an annual decrease in $\mathrm{FEV}_{1}$ of $>90 \mathrm{ml} . \mathrm{s}^{-1}$.

MEASURES OF EXPOSURE AND DECLINE IN LUNG FUNCTION

Exposure levels

Table 4 gives the predicted average decline in lung function expressed as an average decline

Table 4 Results of a regression analysis of decline in lung function on exposure category, corrected for age, standing height, and smoking, in 140 grain processing workers and animal feed workers: annual decline for a 40 year old non-smoker according to exposure category

\begin{tabular}{|c|c|c|c|c|c|c|}
\hline \multirow[b]{2}{*}{ Exposure } & \multicolumn{2}{|c|}{$F V C(m l)$} & \multicolumn{2}{|c|}{$F E V_{1}\left(m l \cdot s^{-1}\right)$} & \multicolumn{2}{|c|}{$M M E F\left(m l . s^{-1}\right)$} \\
\hline & Dust & Endotoxin & Dust & Endotoxin & Dust & Endotoxin \\
\hline $\begin{array}{l}\text { Low } \\
\text { Intermediate } \\
\text { High }\end{array}$ & $\begin{array}{l}-40.7 \\
-57.6 \\
-52.1\end{array}$ & $\begin{array}{l}-45.0 \\
-52.6 \\
-51.7\end{array}$ & $\begin{array}{l}-35.8 \\
-48.6 \\
-58.2^{\star}\end{array}$ & $\begin{array}{l}-36.8 \\
-48.5 \\
-59.0^{\star \star}\end{array}$ & $\begin{array}{l}-28.2 \\
-45.0 \\
-86.7^{\star}\end{array}$ & $\begin{array}{l}-28.9 \\
-51.6 \\
-83.6^{\star \star}\end{array}$ \\
\hline
\end{tabular}

${ }^{\star} \mathrm{p}<0.05 ;{ }^{\star \star} \mathrm{p}<0.10$.

$\Delta$ lung function $=$ interval $+\beta_{1}$.age $+\beta_{2}$.height $+\beta_{3}$.smoking $+\beta_{4}$. (intermediate $)+\beta_{5}$. (high).

Table 5 Results of a regression analysis of decline in lung function on change in exposure category, corrected for age, standing height, and smoking, in 140 grain processing workers and animal feed workers: annual decline for a 40 year old non-smoker according exposure category

\begin{tabular}{|c|c|c|c|c|c|c|}
\hline \multirow[b]{2}{*}{ Exposure } & \multicolumn{2}{|c|}{$F V C(m l)$} & \multicolumn{2}{|c|}{$F E V_{1}\left(m l . s^{-1}\right)$} & \multicolumn{2}{|c|}{$M M E F\left(m l . s^{-1}\right)$} \\
\hline & Dust & Endotoxin & Dust & Endotoxin & Dust & Endotoxin \\
\hline Always low & -29.8 & -40.5 & -29.5 & -34.6 & -31.9 & -29.4 \\
\hline Always high & $-55.4^{\star}$ & -54.9 & $-47.6^{\star \star}$ & $-56.9^{\star}$ & -45.6 & $-73.8^{\star \star}$ \\
\hline High-low & $-55.2^{\star}$ & -51.5 & $-63.7^{\star}$ & $-54.6^{\star \star}$ & $-103.0^{\star}$ & -70.9 \\
\hline Low-high & $-59.5^{\star}$ & -50.8 & -48.2 & -39.4 & -27.9 & -25.1 \\
\hline
\end{tabular}

${ }^{\star} \mathrm{p}<0.05 ;{ }^{\star \star} \mathrm{p}<0.10$.

$\Delta$ lung function $=$ interval $+\beta_{1}$. age $+\beta_{2}$.height $+\beta_{3}$.smoking $+\beta_{4}$. (always high $)+\beta_{5}$. (high-low $)+$ $\beta_{6}$.(low-high). for a 40 year old non-smoker according to exposure category during the 1986-8 survey and the change in exposure category between the two surveys. All three lung function variables showed an increased decline with increasing exposure. For $\mathrm{FEV}_{1}$ and $\mathrm{MMEF}$ this relation was significantly higher for high exposure to dust (>10 mg. $\left.\mathrm{m}^{-3}\right)$ compared with low exposure to dust $\left(<4 \mathrm{mg} \cdot \mathrm{m}^{-3}\right)$ and was of borderline significance for the high exposure to endotoxins compared with no or low exposure to endotoxins. Assuming a cumulative exposure over a working life of 40 years in the grain processing and animal feed industry the estimated effect on $\mathrm{FEV}_{1}$ would be $896 \mathrm{ml} . \mathrm{s}^{-2}$ with an exposure to dust $>10 \mathrm{mg} \cdot \mathrm{m}^{-3}(95 \% \mathrm{CI}$ 65 to 1727 ).

Subjects who either remained in the highest category of exposure to dust or changed to another dust exposure category had a significantly larger decline in FVC (table 5). For exposure to endotoxins a similar, non-significant, trend was found. For FEV ${ }_{1}$ and MMEF the largest decline was found among workers who remained highly exposed or went from jobs with high or intermediate exposure to jobs with lower exposure.

With the derived linear regression equation; a 40 year old non-smoker, with no exposure at the 1986-8 survey would show an annual decline in FVC, $\mathrm{FEV}_{1}$, and MMEF of $45 \mathrm{ml}, 36 \mathrm{ml} . \mathrm{s}^{-1}$, and $25 \mathrm{ml} . \mathrm{s}^{-1}$, respectively. For a worker with an average exposure at the 1986-8 survey the annual decline would be $48 \mathrm{ml}, 43 \mathrm{ml} . \mathrm{s}^{-1}$, and $42 \mathrm{ml} . \mathrm{s}^{-1}$. The differences were significant for $\mathrm{FEV}_{1}$ and MMEF. Table 6 shows the differences in annual decline in lung function related to concentrations of dust and exposure to endotoxins, after adjustment for age and smoking status by linear regression. These analyses show that when a cumulative exposure was assumed over a working life of 40 years with an exposure of $5 \mathrm{mg} \cdot \mathrm{m}^{-3}$, the estimated effect on the $\mathrm{FEV}_{1}$ would be a decline of $157 \mathrm{ml} . \mathrm{s}^{-1}$ (about $4 \%$ of the group mean $\mathrm{FEV}_{1} ; 95 \%$ CI 13 to 300 ) and $473 \mathrm{ml} . \mathrm{s}^{-1}$ on the MMEF (about $12 \%$; $95 \%$ CI 127 to 820 ).

\section{Duration of exposure}

A strong inverse relation between the number of working years in the grain processing and 
Table 6 Regression of annual decline in lung function on exposure levels at 1986-8 survey, corrected for age, standing height, and smoking, in 140 grain processing workers and animal feed workers

\begin{tabular}{|c|c|c|c|c|c|c|c|c|c|}
\hline & \multicolumn{3}{|c|}{$F V C(m l)$} & \multicolumn{3}{|c|}{$F E V_{1}\left(m l . s^{-1}\right)$} & \multicolumn{3}{|c|}{$M M E F\left(m l . s^{-1}\right)$} \\
\hline & $\beta_{4}$ & $S E$ & $R^{2}$ & $\overline{\beta_{4}}$ & $S E$ & $R^{2}$ & $\beta_{4}$ & $S E$ & $R^{2}$ \\
\hline Dust exposure at $1986-8$ survey & -0.219 & 0.418 & 4.0 & $-0.784^{\star}$ & 0.368 & 11.6 & $-2.366^{\star}$ & 0.884 & 7.0 \\
\hline Endotoxin exposure at $1986-8$ survey & -0.122 & 0.158 & 4.2 & $-0.326^{\star}$ & 0.139 & 12.2 & $-0.740^{\star}$ & 0.338 & 5.4 \\
\hline
\end{tabular}

${ }^{\star} \mathrm{p}<0.05 ;{ }^{\star \star} \mathrm{p}<0.10$.

$\Delta$ lung function $=$ interval $+\beta_{1}$.age $+\beta_{2}$.height $+\beta_{3}$.smoking $+\beta_{4}$. (exposure level).

Table 7 Results of a regression analysis of decline in lung function on numbers of years in the grain processing and animal feed industry, corrected for age, standing height, and smoking, in 140 grain processing workers and animal feed workers: annual decline for a 40 year old non-smoker according to number of years in the industry

\begin{tabular}{llll}
\hline $\begin{array}{l}\text { Number of working } \\
\text { years at baseline }\end{array}$ & $\begin{array}{l}F V C \\
(\mathrm{ml})\end{array}$ & $\begin{array}{l}F E V^{-1} \\
\left(\mathrm{ml} . \mathrm{s}^{-1}\right)\end{array}$ & $\begin{array}{l}\mathrm{MMEF} \\
\left(\mathrm{ml} . \mathrm{s}^{-1}\right)\end{array}$ \\
\hline $0-<5$ & -72.3 & -74.7 & -99.1 \\
$5-<10$ & -59.3 & $-51.4^{\star \star}$ & -50.1 \\
$10-<20$ & $-34.7^{\star}$ & $-35.3^{\star}$ & $-23.6^{\star}$ \\
$\geqslant 20$ & $-21.4^{\star}$ & $-17.8^{\star}$ & -32.9 \\
\hline
\end{tabular}

${ }^{\star} \mathrm{p}<0.05 ;{ }^{\star \star} \mathrm{p}<0.10$.

$\Delta$ lung function $=$ interval $+\beta_{1}$.age $+\beta_{2}$.height $+\beta_{3}$. smoking + $\beta_{4}$. (always high $)+\beta_{5}$. (high-low) $+\beta_{6}$. (low-high)

animal feed industry and decline in lung function was found, which was even stronger when the regression analysis was restricted to the period before the first survey. Table 7 gives the decline in predicted lung function for a 40 year old non-smoker according to the number of years worked in the industry before the 1986-8 survey. The annual decline in lung function showed an inverse relation with the number of working years before the first survey; the decline decreased with increasing number of years in the industry. The strongest relation was found for $\mathrm{FEV}_{1}$. For a 40 year old, lifetime non-smoker the annual decline in $\mathrm{FEV}_{1}$ would be about $75 \mathrm{ml} \cdot \mathrm{s}^{-1} \cdot \mathrm{y}^{-1}$ for $<5$ working years; 51 $\mathrm{ml} . \mathrm{s}^{-1} \cdot \mathrm{y}^{-1}$ for $5-10$ working years; $35 \mathrm{ml} \cdot \mathrm{s}^{-1} \cdot \mathrm{y}^{-1}$ for $10-20$ working years; and $18 \mathrm{ml} \cdot \mathrm{s}^{-1} \cdot \mathrm{y}^{-1}$ for $>20$ working years in the grain processing and animal feed industry. When the analyses were repeated with the number of years exposed, the largest decline was in the workers who had been exposed for 5-10 years, significantly larger than the decline among workers exposed for $<5$ years. Workers with longer exposure showed an increased annual decline compared with workers with no exposure or $<5$ years of exposure, but the differences did not reach significance. Stratification into age groups did not improve the models, either in terms of significance or explained variance.

MEASURES OF EXPOSURE AND DECLINE IN FEV $>90 \mathrm{ML} \cdot \mathrm{S}^{-1} \cdot \mathrm{Y}^{-1}$

Nineteen workers $(14 \%)$ had a rapid annual decrease in $\mathrm{FEV}_{1}>90 \mathrm{ml} \cdot \mathrm{s}^{-1}$. With logistic regression analysis relations between several exposure measures and a rapid decline in $\mathrm{FEV}_{1}$ were found - that is, workers with exposure to a concentration of dust of $>4 \mathrm{mg} \cdot \mathrm{m}^{-3}$ at the 1986-8 survey had an odds ratio (OR) of 3.3 (95\% CI 1.02 to 10.3$)$ for having a rapid decline in $\mathrm{FEV}_{1}$. For workers with an exposure to concentrations of endotoxins $>20 \mathrm{ng} \cdot \mathrm{m}^{-3}$ the OR was 3.2 (CI 1.1 to 9.2 ).
RESPIRATORY SYMPTOMS, LUNG FUNCTION, AND LOSS TO FOLLOW UP

Age and respiratory symptoms were found to be the strongest predictors of loss to follow up. No significant relations between lung function and loss to follow up have been found with lung function as the sole explanatory variable or in combination with other explanatory variables.

Exposure to dust or endotoxin showed no significant association with subsequent loss to follow up. Simultaneous comparison of workers with high and intermediate exposure at the time of the 1986-8 survey with workers with no or low exposure resulted in an OR of 0.78 $(\mathrm{p}=0.49)$ for high dust exposure and 1.68 $(\mathrm{p}=0.06)$ for intermediate dust exposure and ORs of $0.76(p=0.47)$ and $1.12(p=0.14)$ for high and intermediate exposure to endotoxins, respectively.

The effect of confounders, exposure proxies, and respiratory symptoms on the $\mathrm{FEV}_{1}$ at the 1986-8 survey were compared with linear regression analysis between the 140 workers studied longitudinally and the 156 workers lost to follow up. Between those groups the strength of the relation between exposure to dust or presence of respiratory symptoms and of $\mathrm{FEV}_{1}$ was different. Among those lost to follow up, lung function was more affected by the presence of respiratory symptoms whereas among the workers in the longitudinal analysis exposure to dust had a stronger effect on the $\mathrm{FEV}_{1}$. The effect of exposure to endotoxin $>20$ ng. $\mathrm{m}^{-3}$ was similar in both groups.

In both groups there was a positive correlation between the decrement in $\mathrm{FEV}_{1}$ at the 1986-8 survey and the number of working years; the lung function of workers with $>20$ years work experience in the grain processing and animal feed industry showed the largest decrements compared with workers who worked $<5$ years in the industry. Workers with 5-10 years experience and 10-30 years showed intermedi-

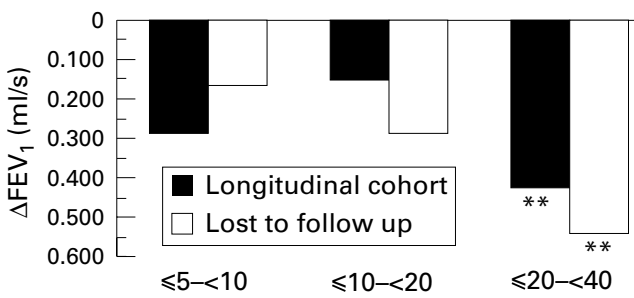

Work-years in animal feed before survey 1

Differences in baseline $F E V$, for number of working years for 140 workers remaining in the grain processing and animal feed industry and 156 workers lost to follow up, corrected for age, standing height, and smoking (baseline $F E V_{1}=\beta_{1}$. age $+\beta_{2}$. height $+\beta_{3}$. smoking $+\beta_{5 .}(5-10$ working years $)+\beta_{6} \cdot(10-20$ working years $)+\beta_{7 .}(>20$ working years)). 
ate decrements, but were not significantly different from workers who had worked $<5$ years in this industry (figure).

\section{Discussion}

RELATION BETWEEN EXPOSURE AND DECLINE IN LUNG FUNCTION

In this study, exposure in the grain processing and animal feed industry is related to change in $\mathrm{FEV}_{1}$ and MMEF. Higher exposure to dust and endotoxin resulted in higher declines in $\mathrm{FEV}_{1}$ and $M M E F$, which were significantly different from the decline in lung function in workers with no or low exposure. Assuming a lifelong exposure of 40 years, the effect of exposure to concentrations of dust $>10 \mathrm{mg} \cdot \mathrm{m}^{-3}$ on the $\mathrm{FEV}_{1}$ would be almost $900 \mathrm{ml} . \mathrm{s}^{-1}(95 \%$ CI 65 to 1727).

A significant relation between decline in $\mathrm{FEV}_{1}$ and MMEF and cumulative exposure proxies was also found. Assuming a cumulative exposure over a working life of 40 years with an exposure at the first survey of $5 \mathrm{mg} \cdot \mathrm{m}^{-3}$, the estimated effect on the $\mathrm{FEV}_{1}$ would be about $4 \%$ of the group mean $\mathrm{FEV}_{1}$. The effect on the MMEF would be about $12 \%$ of the group mean MMEF. These figures are lower than using categorical exposure proxies, but are in agreement with the earlier cross sectional analysis of Smid et al. ${ }^{5}$

Comparison of $\mathrm{FEV}_{1}$ measurements in grain handlers with data from a general population study indicates that workers exposed to grain dust have yearly losses in lung function greater than would be expected in an unexposed population. A cumulative effect of exposure has been suggested by Tabona et $a l^{12}$ who found that decrement in lung function was greater in older grain handlers. Later research by Enarson et al showed that the higher the dust concentration, the higher the likelihood of a rapid decline in lung function. ${ }^{10}$ Workers with the worst trend in spirometry over a six year period showed an average rate of decline in $\mathrm{FEV}_{1}$ of $100 \mathrm{ml} \cdot \mathrm{s}^{-1} \cdot \mathrm{y}^{-1}$. The study of Pahwa et al suggested a positive relation between annual loss of lung function and number of years in the grain industry, levelling off during the later years of employment. ${ }^{4}$ Mean annual loss of $\mathrm{FEV}_{1}$ and $\mathrm{FVC}$ was 9.2 and $21 \mathrm{ml} \cdot \mathrm{s}^{-1} \cdot \mathrm{y}^{-1}$ for workers in the industry $<5 \mathrm{y}$, and increased to 52.6 and $60.8 \mathrm{ml} \cdot \mathrm{s}^{-1} \cdot \mathrm{y}^{-1}$ for workers in the industry for $>20 \mathrm{y}$. The $\mathrm{FEF}_{25-75}$ showed a similar trend.

Other recent studies on grain dust have indicated that impairment of lung function is related to cumulative grain dust exposure as well as to the duration of exposure. ${ }^{25}$ Huy et al found an apparent dose-response trend among the workers exposed to grain for annual change in $\mathrm{FEV}_{1}$ and MMEF. ${ }^{2}$ They also found that the control group showed annual changes in FVC, $\mathrm{FEV}_{1}$, and MMEF comparable with those found in the group exposed to intermediate concentrations of grain dust. Smid et al found decreased lung function values with increasing exposure to both dust and endotoxin in a cross sectional study. The number of years employed in the animal feed industry and estimated cumulative exposure were clearly related to lung function.

Another finding of the previous analyses is that both symptoms and lung function were more clearly related to exposure to endotoxins than to dust. In the current analyses, dust and endotoxin have, in general, effects of similar magnitude on lung function. In longitudinal studies of lung function, test variability usually exceeds annual variability, which might reduce the power of the study and make it more difficult to detect differences in effect of dust and exposure to endotoxins on decline in lung function.

Buist and Vollmer concluded that to develop clinically notable airflow obstruction the average yearly rate of decline in $\mathrm{FEV}_{1}$ over an adult life probably needs to be $>90 \mathrm{ml} \cdot \mathrm{s}^{-1} \cdot \mathrm{y}^{-1}$ or about three times that found in non-smokers. ${ }^{18}$ In the present study, despite the limited number of subjects with rapid decline in $\mathrm{FEV}_{1}$, defined as an annual decline $\geqslant 90 \mathrm{ml} . \mathrm{s}^{-1}$, rapid decline in $\mathrm{FEV}_{1}$ was significantly related to exposure to dust and endotoxin, with ORs around 3.2 at exposure to concentrations of dust of $\geqslant 4$ $\mathrm{mg} . \mathrm{m}^{-3}$. The analyses show that being exposed at either survey or both resulted in an excessive decline, compared with the workers with low exposure on both surveys. It is likely that acute and chronic effects intermingle. This is in agreement with the earlier observation that both present and previous exposures are important predictors of decline in lung function. ${ }^{5}$

HEALTHY WORKER EFFECT

In the earlier study in the grain processing and animal feed industry by Smid et al some results were indicative of selection processes interacting with obvious exposure effects. ${ }^{5}$ In other studies the healthy worker effect has also been found..$^{1311}$ In the analyses of five cross sectional studies among grain elevator workers, grain workers as well as civic workers who took part in all five surveys over a period of 12 years were found to be a selected healthier group. ${ }^{3}$ The mean lung function of this subgroup was higher than the lung function of workers in cross sectional surveys. Furthermore, the mean lung function of workers participating in all studies increased over the observation period.

In the present analysis the healthy worker effect has also been found. There was a negative association between decline in lung function and number of years in the grain processing and animal feed industry; the decline in lung function decreases with increasing working years (table 7). The ORs of rapid decline also decreased with the number of working years. Compared with the workers with $<5$ years in the grain processing and animal feed industry, workers with $>20$ years had a significantly decreased OR of 0.04 (95\% CI 0 to 0.61 ).

LOSS TO FOLLOW UP

The healthy worker effect can be studied by comparing workers remaining in the industry with workers who have left the industry. Therefore, workers who participated in both surveys were compared with workers who 
participated in the first survey only. These consisted mainly of workers who were no longer working in the industry, but also of workers who were unable to attend, due to holidays, work load, or illness.

Age and respiratory symptoms were found to be the strongest predictors of loss to follow up. Although workers who were studied longitudinally had a significantly higher lung function at the first study than those workers who were lost to follow up (table 3), no significant effect of lung function at the first survey on subsequent loss to follow up could be found when age was included in the model as well. This discrepancy between symptoms and lung function was also found in the earlier study. ${ }^{5}$ The present analyses confirm the possible explanation for this discrepancy put forward by Smid et al that the healthy worker effect might be more pronounced for people with perceived symptoms than for people with minor changes in lung function.

No significant relations between exposure to dust and endotoxin and subsequent loss to follow up could be found. However, changing the cut off between high and low exposure suggested that in subjects with the highest levels of exposure selection might have taken place, resulting in healthier workers, although in workers with intermediate exposures the selection processes are still occurring.

The influence of age, smoking status, respiratory symptoms, and exposure on $\mathrm{FEV}_{1}$ at the first survey was compared between workers who were studied longitudinally and the workers who were lost to follow up. Smid et al found a significant decrease in lung function with an increase in production years. For $\mathrm{FEV}_{1}$ a difference of $0.141 . \mathrm{s}^{-1}$ (SE 0.04) was found for 10 years of production work. ${ }^{5}$ The current analyses show that this relation is stronger in workers who were lost to follow up than in workers who were studied longitudinally. In the workers who were studied longitudinally a difference of $0.151 . \mathrm{s}^{-1}$ (SE 0.07) was found for 10 years in the industry. In workers who were lost to follow up the difference was $0.171 . \mathrm{s}^{-1}$ (SE 0.11 ).

In conclusion, the current analysis shows a relation between occupational exposure in the grain processing and animal feed industry and decline in lung function over a five year period. Decline is related to concentrations of dust and endotoxin and the decline in lung function between the two surveys is also affected by exposure before the first survey. This was shown with proxies for cumulative exposure. The results of this study should be interpreted by considering the influence of the healthy worker effect. Obviously, the selection processes weaken the relations we found between exposure and decline in lung function, probably diminish the power to detect respiratory disorders, and may lead to an underestimation of exposure-effect relations, and consequently the health risks for workers in the grain processing and animal feed industry.

1 Zuskin E, Schachter EN, KanceljakB, et al. Organic dust disease of airways. Int Arch Occup Environ Health 1993;65:135-40.

2 Huy T, de Schipper K, Chan-Yeung M, et al. Grain dust and lung function. Dose-response relationships. Am Rev Respir Dis 1991;144:1314-21.

3 Chan-Yeung M, Dimich-Ward H, Enarson A, et al. Five cross-sectional studies of grain elevator workers. Am $\mathcal{F}$ Epidemiol 1992;136:1269-79.

4 Pahwa P, Senthilselvan A, McDuffie $\mathrm{HH}$, et al. Longitudinal estimates of pulmonary function decline in grain workers. Am $\mathcal{F}$ Respir Crit Care Med 1994;150:656-62.

5 Smid T, Heederik D, Houba R, et al. Dust- and endotoxinrelated respiratory effects in the animal feed industry. $\mathrm{Am}$ Rev Respir Dis 1992;146:1474-9.

6 Clapp WD, Becker S, Quay J, et al. Grain dust-induced airflow obstruction and inflammation of the lower respiratory tract. Am f Respir Crit Care Med 1994;150:611-7.

7 Rylander R. Organic dusts and lung reactions-Exposure characterstics and mechanisms for disease. Scand f Work Environ Health 1985;11:199-206.

8 Jacobs RR. Airborne endotoxins: an association with occupational lung disease. Appl Ind Hyg 1989;4:50-6.

9 Kennedy SM, Christiani DC, Eisen EA, et al. Cotton dust and endotoxin exposure - response relationships in cotton textile workers. Am Rev Respir Dis 1987;135:194-200.

10 Enarson DA, Vedal S, Chan-Yeung M. Rapid decline in $\mathrm{FEV}_{1}$ in grain handlers. Relation to level of dust exposure. Am Rev Respir Dis 1985;132:814-7.

11 Zedja JE, Pahwa P, Dosman JA. Decline in spirometric variables in grain workers from start of employment: differential effect of duration of follow up. Br $\mathcal{F}$ Ind Med 1992;49:576-80.

12 Tabona $M$, Chan-Yeung M, Enarson D, et al. Host factors affecting longitudinal decline in lung spirometry among grain elevator workers. Chest 1984;85:782-6.

13 Kateman E, Heederik D, Pal TM, et al. Relationship of airborne microorganisms with the lung function and leucocyte levels of workers with a history of humidified fever. Scand $\mathcal{F}$ Work Environ Health 1990;16:428-33.

14 Quanjer PH, ed. Standardized lung function testing. Report of the working party standardization of lung function tests. Bulletin Européen Physiopathologie Respiratoire 1983; 19(suppl 5):1-95.

15 Vollmer WM, Johnson LR, McCamant LE, et al. Longitudinal versus cross-sectional estimation of lung function nal versus cross-sectional estimation of lung func

16 Burrows B, Lebowitz MD, Camilli AE, et al. Longitudinal changes in forced expiratory volume in one second in adults. Methodological considerations and findings in healthy nonsmokers. Am Rev Respir Dis 1986;133:974-80.

17 Glindmeyer HW, Diem JE, Jones RN, et al. Noncomparability of longitudinal and cross-sectionally determined annual change in spirometry. Am Rev Respir Dis 1992;125:544-8.

18 Buist AS, Vollmer WM. The use of lung function tests in identifying factors that affect lung growth and aging. Stat Med 1988;7:11-8. 